Check for updates

The BMJ

Cite this as: $B M J 2020 ; 371: m 4964$ http://dx.doi.org/10.1136/bmj.m4964 Published: 30 December 2020

\title{
Covid-19: Doctors must be vaccinated without delay, says BMA
}

\section{Abi Rimmer}

The BMA has called for frontline healthcare staff to be given the covid-19 vaccine as soon as possible.

The call came just a day before the UK Medicines and Healthcare Products Regulatory Agency (MHRA) approved the Oxford-AstraZeneca vaccine on 30 December.

In a letter sent on 29 December to the NHS chief executive Simon Stevens, ${ }^{1}$ the association said that doctors around the country had reported having no notification of when they would be vaccinated.

Others reported that, while vaccinations were being given, this was being done sporadically and without prioritisation. This was despite healthcare workers being listed in the same priority group as over $80 \mathrm{os}$ in guidance from the Joint Committee on Vaccination and Immunisation, ${ }^{2}$ the BMA said. The same guidance applies to the Oxford-AstraZeneca vaccine.

Chaand Nagpaul, BMA council chair, wrote, "If healthcare workers fall ill from being infected and are unable to work it will be devastating for the health service at this time of critical pressures and will compound the problems hospitals and general practices are already struggling with, regarding staff shortages. There is also a very real risk of this impeding the rollout of the vaccine itself, which is reliant on delivery by healthcare staff."

He called for assurances that frontline staff would be vaccinated in a clearly defined, systematic, and prioritised way.

\section{Prioritisation}

Welcoming the approval of the Oxford-AstraZeneca vaccine, Andrew Goddard, president of the Royal College of Physicians, also called for staff vaccinations to be expedited.

"Frontline NHS and care staff must be vaccinated in the next couple of weeks as a priority, as the current pressures on the NHS will be impossible to withstand without a fit and protected workforce," he said.

Despite the BMA's concerns the rollout of vaccinations for NHS staff has been working well in some areas. Alison Pittard, dean of the Faculty of Intensive Care Medicine, told The BMJ that a lot of trusts had put their own prioritisation in place for the distribution of any leftover vaccine to staff, after it had been given to the allocated people.

Discussing how the prioritisation would work, Pittard said, "critical care, emergency departments, and acute medical units will be more at risk of seeing covid patients, so they would be top of the priority list.

"Within those departments there will be healthcare workers who are more vulnerable than others, so those who are clinically vulnerable, those from ethnic minority backgrounds, and different age brackets will dictate how they prioritise staff.

"I assume that this is how the majority of trusts are trying to make sure that the vaccine they have is used most efficiently. I work in Leeds, and that is what is happening here."

\section{Isolating staff}

Pittard added that vaccinating staff would allow them to continue to care for patients even if they had come into contact with someone with the virus.

"One of the big issues is not necessarily doctors themselves catching covid, but it's doctors having to isolate because a member of their family, for example, has been in contact with the virus," she explained. "As more people get vaccinated it is going to relieve some of the pressure on staff having to isolate. And staffing is the main issue in terms of keeping beds open."

The BMA conducted a survey of 7776 doctors and medical students from 14 to 17 December. Of the 6254 respondents to a question on whether clinical colleagues had been on sick leave or self-isolating in the past two weeks, 1407 (22.5\%) said that they had-and that it had a significant impact on patient care.

Just under a third (1789; 28.6\%) said that these absences had had a moderate impact on patient care, while a quarter $(1513 ; 24.2 \%)$ had been able to manage the impact.

Under a fifth $(1163 ; 18.6 \%)$ reported no clinical colleague absences due to sick leave or self-isolation, and $383(6.1 \%)$ said that they didn't know.

1 BMA. Letter to Simon Stevens. 29 Dec 2020. https://www.bma.org.uk/media/3628/bma-letter-to-simon-stevens-vaccineprioritisation-291220.pdf.

2 Department of Health and Social Care. Vaccine priority groups: advice on 2 December 2020. Dec 2020. https://www. gov.uk/government/publications/priority-groups-for-coronavirus-covid-19-vaccination-advice-fromthe-jcvi-2-december-2020/priority-groups-for-coronavirus-covid-19-vaccination-advice-from-the-jcvi-2-december-2020\#vaccine-priority-groupsadvice-on-2-december-2020.

This article is made freely available for use in accordance with BMJ's website terms and conditions for the duration of the covid-19 pandemic or until otherwise determined by BMJ. You may use, download and print the article for any lawful, non-commercial purpose (including text and data mining) provided that all copyright notices and trade marks are retained. 